\title{
ОБЗОРЫ
}

\section{CONCEPT OF SUICIDE: NEUROPHYSIOLOGICAL/GENETIC THEORIES AND POSSIBLE OXYTOCIN RELEVANCE}

\author{
Received May 15, 2015
}

The suicidal behavior is regarded as the act by which a person seeks to take his life, being aware of the consequences of his action. In our review, besides describing the main introductory aspects for the concept of suicide, we focus our attention on the main neurophysiological and genetical mechanisms relevant for this extremely difficult to manage and controversial behavior. Moreover, considering the latest interests in the current literature on the relevance of central oxytocin to various superior cognitive behaviors, we will also make a short description on how important effects of oxytocin could be in the context of suicidal behavior.

\section{Keywords: suicide, neurophysiological and genetic mechanisms, oxytocin.}

\section{INTRODUCTION}

\section{THE CONCEPT OF SUICIDE}

The suicidal behavior is regarded as the act by which a person seeks to take his life, being aware of the consequences of his action [1]. Thus, suicide can be regarded as a rationally executed act, based on moral, social, religious, philosophical and/or personal reasons. Conversely, suicide may be seen as a pathological act, which occurs during the development of various mental disorders (e.g., depression, persistent delirium, dementia, confusion, etc.), or in the context of an acute existential crisis in which the manifestations may take the form of an auto-aggressive anxious raptus. These raptuses are spontaneous, unpredictable, and are manifested extremely rapidly, as compared with the premeditated suicide of patients with melancholic depression or in the context of systematized deliria [2]. Overall, regardless of motivations and context (e.g., social, family, or personal), the concept of suicidal ideation refers to a person's thoughts to take his/her own life.

The World Health Organization defines suicide as an act by which an individual seeks for his/her physical

\footnotetext{
${ }^{1}$ Gr. T. Popa University of Medicine and Pharmacy, Iasi, Romania.

${ }^{2}$ Alexandru Ioan Cuza University, Iasi, Romania.

${ }^{3}$ Center of Biomedical Research of the Romanian Academy, Iasi, Romania. Correspondence should be addressed to D. Timofte

(e-mail: dantimofte@yahoo.com).
}

self-destroy, with the more or less authentic intention to waste his/her life or being more or less conscious of the rationale of the gesture [3]. Interpreted more broadly, the concept of suicide can also refer to any action, tendency, or behavior of self harm (including the so-called "chronic suicide " of drug addicts, alcoholics, or individuals with mental anorexia) that by certain self-destructive behaviors of repetitive cyclical-nature attempts to finish the personal life. Also, in a narrow interpretation, the suicide is the act of global self-destruction, of sudden suppression of one's own life, intentionally, willfully, knowingly, and considering death as a total and inexorable ending.

In fact, suicide is the expression of an acute crisis of conscience that expresses a subjective-affective tension between the individual and the group, favored by situational factors, with the ability to precipitate the autolytic gesture in a fragile and vulnerable personality [4]. In this way, Douglas [5] defines suicide from a double perspective, both psychological and sociological, addressing rather a concept than an operational definition. Douglas reveals the five dimensions of the suicidal act, namely initiative, motivation, intention, will, and desire. According to Scripcaru et al. [6], the suicide definition would represent a tempted or actual behavior expressing a psycho-emotional tension between the individual and the social group, triggered or precipitated by circumstantial factors with a consciously designed self-destruction idea. In addition, other theorists 
consider suicide a disruption of homeostasis in the individual/environmental relation and deciphering its code depending on the visibility and understandability of its forms of expression. Thus, in some individuals a death will is certain, while in others it is uncertain, in some it is impulsive, in some it can be cyclical, in some it is chronic, persistent, and in others the wish to die is acute, transient, with or without a repeatability trend.

The concept of suicidal behavior refers to the technical support, consisting of the preparatory work for staging the suicidal act, the steps and settling the suicidal plan. Choosing the manner of ending one's own life is determined by many factors, such as effectiveness, speed, ease of execution, imitation, keeping physical appearance and bodily integrity, availability of the suicidal method, and sometimes also by limiting as much as possible the beforehand suffering and anguish. To ensure the success of the method, the most efficient approach will be adopted in accordance with the availability and access to certain types of methods. But ultimately, the choice of the suicidal means is determined by the significance of the act and the mental condition of the person at the time when committing suicide. The effectiveness of the chosen means is regarded as revealing the authenticity of the suicide attempt. Traditionally, it is considered that the main autolytic means are traumatic (defenestration and shooting), asphyxia (gas inhalation, submersion, strangulation), and toxic (ingestion of the respective substances) [7].

Also, certain aspects due to cultural differences should be mentioned when choosing other variants of self harm. Thus, while in China the poisoning with opium and salts of arsenic is frequent, in Japan the traditional seppuku was replaced by the use of firearms, while in France the order of the most commonly used methods is hanging, drowning, and using firearms [8].

Below, we will briefly review the main methods used in suicidal behavior. One such method involves exsanguination by damaging the easy to access arteries (radial, ulnar, carotid, or femoral), wich causes hypovolemia below the critical level leading to a circulatory collapse. Chronic suicide attempts, parasuicide, or self-mutilation attained in the same manner can be assessed by looking for traumatic marks (scars) at the level of these arteries. Also typical of this type of conduct is a large number of injuries [9]. In addition, suicide by hanging involves two types of mechanisms, depending on the length of the drop. Thus, one of the mechanisms that occurs in the short drop achieves death by hypoxia through the compression of the carotid artery and jugular vein. For the longer drops, vertebral fractures can occur, often in the C5-C6 vertebrae, which cause death or paralysis in the survivors [10].

Another autolytic method used by suicidal persons is by jumping from high buildings, through windows (defenestration), from bridges or cliffs. This is frequent especially in the areas with increased accessibility to these kind of methods. For example, in Hong Kong, where there are a large number of high buildings, more than half of the deaths by suicide are executed through this method [11]. This autolytic approach is associated with a high risk of severe consequences in the case of a failed suicide, such as paresis, paralyses, bone fractures, and severe damages to internal organs.

Another method of suicide used relatively frequently involves the use of firearms. The use of firearms in suicide attempts is more common in people who routinely possess firearms, but also in countries with permissive legislation on firearms possession [12]. However, it is doubtful to believe that the legislative restrictions concerning the firearms possession would lead to lower overall rates of suicide. The decrease of certain methods of suicide by reducing the access possibilities could lead to increased rates of other types of methods as a compensatory mechanism.

Suicide produced by asphyxia is often achieved by exposure to certain toxic gases, such as carbon monoxide. This produces a quick death as it rapidly induces unconsciousness state preventing an eventual change of mind of the suicidal person [13].

Suicide by drowning is relatively rare, as compared to other autolytic methods. A study conducted on the US population reported less than $2 \%$ of suicide deaths as caused by drowning. The mechanism of death consists in the acute oxygen deprivation of the brain by immersion in water that impedes the breathing process.

Other common suicidal methods include drug overdose, traffic accidents, electrocution, or poisoning. Also, as previously mentioned, the modern trend concerning the growing use of hallucinogens suggests that drug addiction can be a passive form of selfdistructive behavior. The chronic use of hallucinogens, naturally, has strong negative consequences on health.

Very interestingly, a research on the places selected for accomplishing the suicide reported that about $44 \%$ 
of suicidal acts are performed at home; public places; hotels, and working places are less preferred [14]. In this way, such aspects could represent an important lead when intending to oversee and prevent a person known with a high risk of suicide.

According to Stengel [15], the genuine suicidal act unfolds as follows: the occurrence of one's decision to end his/her lives or the impulsive action to self-kill, using for this the most efficient methods and taking all the safety measures that nobody will interfere. If death occurs, it is considered a successful suicide attempt; if the person survives, the act would be considered a failed suicide one. As death is the only purpose of the act, it should be considered the criterion for success. The failure may be caused by any of the following: motivation is not strong enough; the act has not been well prepared (either due to lack of total conviction on completing the act, or because of lack of knowledge on the limits of the chosen method, lack of judgment, and determination because of a mental illness). According to these criteria, only a part of the accomplished suicidal acts and only a small part of those unfinished can be considered genuine acts of suicide. However, even in the suicidal acts where the person is not fully committed to end his life, a significant number of cases come to completion, while the rest remain as unclear trends or insufficient efforts, ending rather by accident than by determination in action.

In this way, it could be stated that suicide is actually the action of taking one's own life, while a suicide attempt or non-fatal suicidal behavior refers to selfharming in order to take one's own life, but that does not lead to death. The differences between assisted suicide and euthanasia, types of suicide that require another person in order to be completed, should also be mentioned. The assisted suicide occurs when a person indirectly helps another to end his/her life, by providing advices or means for the suicidal act, and it differs from euthanasia, in which the other person is playing a more active role in causing someone's death.

In most cases, the completed suicide follows repeated suicide attempts. A large number of patients who died by suicide have a history of autolytic suicide attempts or even suicidal ideation. Sometimes, the suicidal people have in their family relatives with suicide attempts or completed suicide, which may account for models in their autolytic behavior. Attempted suicide is actually the missed (failed) suicidal act. The attempts may be the expression of a compulsion, can have a demonstrative value, or embody the expression of a punitive act. In fact, clinical studies have shown that suicidal attempts are 8-10 times more common in young people than in adults and about 5-10 times more often in women than in men, the ratio decreasing with age [16].

In general, the suicidal tendencies are explained by self-aggression, and the suicidal impulse explains the suicide as an expression of an irresistible trend. The irresistible suicidal impulse drives the individual to make use of the first means he/she comes across, in opposition to the former suicide plan. Often, the suicide attempts leave long-term physical consequences, which can be very different depending on the autolytic method. Thus, some serious physical sequelae may occur following autolytic attempts, such as mutilation, fractures, severe locomotor, psycho-sensorial, or mental disabilities (e.g., dementia after oxygen deprivation), or functional disabilities (paralysis).

In this way, Biberi [17] considers the suicide as a bio-psycho-social dimensional phenomenon representing an act requiring the deviation for one of the most deeply rooted instinct of the biological structure. In a dramatic situation in which the vital instinct is denied (out of which the subject does not see any escape), suicide becomes the only solution to avoid its unbearable conditions.

Also, according to Menninger [18], the suicide encompasses the three desires that could foster a suicidal act, namely the desire to kill, the desire to be killed, and the desire to die. The desire to kill may be directed not only against an object of love, but also against the internal space. In fact, the conclusions of some long-term clinical trials showed that suicide is sometimes intended to destroy the lives of survivors, as an act of revenge against the others. For example, depressed patients often feel that suicide is the only satisfactory revenge. Sometimes, this act is directed against the parents, brothers, or the partner, and the act is intended to produce suffering of the latter.

In other cases, aggression plays a much more modest role in terms of motivating the suicide. Thus, Fenichel [19] noted that suicide could mean the fulfillment of a desire to reunite. Losing a loved one is often behind suicidal behavior, and many suicidal patients exhibit strong desires of dependence on the lost person. From this point of view, the suicide may be a regressive desire to reunite with a lost figure. Sometimes, a pathological process of mourning is involved, especially in attempts to commemorate the death of a loved one. In this way, there are some ideas that it could be a correlation between suicide and the commemoration for the death of a parent. 


\section{EPIDEMIOLOGICAL ASPECTS}

The suicidal behavior is considered a psychiatric emergency. Virtually, all psychiatric disorders can sometimes generate either spontaneous auto-aggressive and hetero-aggressive outbursts on a background of high psychoemotional tension or, by contrary, planned and idealized previously of the act. The demographic analysis of the completed suicide shows that, generally, the chosen suicide method depends on the geographical area and availability of the method, but also on certain personal factors. Among the chosen suicide methods, the most commonly used seems to be hanging, probably due to the easy access to material, as compared to other methods. A study conducted in 56 countries found hanging as the prevailing method of suicide in most countries [20]. This method was employed by $53 \%$ of men and $39 \%$ of women [21].

Also, a relatively high number of suicides have been recorded as a result of drug overdose, the cause of about $60 \%$ of the suicide cases in women and $30 \%$ in men [22]. Frequently, the suicide by overdose is not previously planned, or it occurs during a period of acute ambivalence. The difference between sexes regarding this method supports the idea of a higher frequency of planned suicide in men. The most often tried methods differ from the most often successful methods; up to $85 \%$ of suicide attempts in the developed countries consist in ingesting an overdose of drugs [23].

Moreover, the studies are generally indicating different percentages regarding the type of suicidal methods. A meta-analysis concerning the most frequent suicide methods identified shooting in $80-90 \%$ cases, drowning $65-80 \%$, inhalation of an exhaust gas 40 $60 \%$, jumping from height $35-60 \%$, and pesticides $6-75 \%$ [24].

Also, a regional analysis of the methods and frequency of suicide methods showed that, $57 \%$ of suicides in the United States, involve the use of a firearm, the percentage being distinctly higher in men than in women. A second cause of suicide in men is hanging, while in women this is poisoning. In Switzerland, the most common suicidal method is the suicide by hanging [25], while in Hong Kong and Singapore, suicide by jumping from height is very common, with rates ranging from $50 \%$ in Hong Kong to $80 \%$ in Singapore [24]. Moreover, in Japan, suicide by hanging is the most common method [26], but also the traditional suicide by disembowelment known as seppuku, or harakiri, is still used nowadays.

\section{NEUROPHYSIOLOGICAL MECHANISTICS AND THEORIES OF SUICIDE}

In this way, among the most investigated biological systems related to the suicidal behavior is the serotonergic system. The researches focused on the levels of serotonin, its metabolite (5-hydroxyindoleacetic acid, 5HIAA), its receptors (5HT2A), and its carrier (5HTT) in platelets. There are also several studies that have compared the whole blood- or platelet- levels of 5HT in patients with mood disorders and a suicide risk. Thus, Roggenbach et al. and the group led by Mann [35, 36] reported decreased serotonin levels in blood platelets in suicidal patients with real suicide attempts, as compared to patients with suicidal ideation only or without autolytic attempts and also non-suicidal patients.

Also, Almeida-Montes et al. [37] reported significantly decreased serum levels of 5HT in depressed patients who attempted suicide, when compared with depressed patients without suicide attempts. Moreover, in a meta-analysis by Lester [38] on a CSF serotonin metabolite, the authors found significantly lower levels of 5HIAA in the patients with previous suicide attempts, as well as in those who subsequently committed suicide or attempted this. In addition to low CSF 5-HIAA levels, the persons who committed suicide showed also an increased number of binding sites for serotonin. In terms of the autolytic ideation intensity, Tyano et al. [39] also found a negative correlation between plasma levels of 5HT and the severity of suicidal behavior in patients.

In addition, determining the 5HT receptors in suicidal patients or those with affective disorders led to the extensive study of the 5HT2A receptor. In this way, the $5 \mathrm{HT} 2 \mathrm{~A}$ receptor seems more likely to be modified in patients with depressive disorders and suicidal ideation. In general, the $5 \mathrm{HT} 2 \mathrm{~A}$ receptors were examined in blood platelets by radioligand binding techniques, and the pharmacological profile of the 5HT2A receptors in the platelets appears to be very similar to that observed in the brain [39].

Even more, Pandey and his collaborators [40] studied the platelet levels of 5HT2A receptors in patients with affective disorders with and without autolytic ideation. In the first instance, the level of 5HT2A receptors was found to be higher in depressed patients, as compared with control subjects. Also, the 5HT2A receptor density was even higher in depressed patients with suicidal behavior, when compared to depressed patients without suicidal ideation. When 
analyzing whether the increase of the 5HT2A receptors in the depressed suicidal patients is independent or not diagnostic and by examining the 5HT2A receptor levels in patients with various psychiatric diagnoses (such as depression, bipolar depression, manias, schizoaffective disorder, or schizophrenia), the authors also noted that the average receptor density in the total group of suicidal patients was significantly higher than that in non-suicidal patients or in the control group. Also, the receptor density was significantly higher in the patients with psychiatric disorders and autolytic ideation, as compared with control subjects. In addition, this study [40] suggested the increase of the platelet 5HT2A receptor density in suicidal patients, irrespective of the diagnosis.

In addition, numerous evidences supported the involvement of the 5-HT1A receptor in the formation of suicidal behavior. The important role of 5-HT1A receptors in suicidal behavior was in this way assayed by studying the changes of these receptors in the postmortem brains of the suicide victims. In this way, the results showed that binding to the 5-HT1A receptors was found to increase in the cortex of suicidal patients with major depression, but no change in binding to these receptors was observed in the frontal lobes, occipital cortex, hippocampus, and amygdala of depressed suicidal patients [41, 42]. These discrepancies could be explained by the intervention of other factors, such as gender, presence or absence of affective disorders, or ethanol consumption (as we would like to insist immediately on this important factor).

Also, the involvement of the serotonergic system in suicidal behavior seems to correlate with specific nervous areas, such as the forebrain, medial prefrontal cortex, orbitofrontal cortex, amygdala, and nucl. accumbens [43]. In this way, the postmortem studies of suicidal persons reported fewer serotonin transporters in the prefrontal cortex, hippocampus, occipital cortex, and brainstem [44].

We should also mention that the relationship between serotonin and aggressiveness [45] is an important aspect in studying the neurobiological underpinnings of suicide, especially in violent suicide cases. In fact, suicidal behavior is influenced by many biological variables that modify the serotonergic neurotransmission, including the psychosocial stress, traumatic experiences, pathological personality traits, disorders, or the alcohol abuse [46, 47].

Regarding the latter mentioned aspect, it is well known that alcoholism can be found in most psychiatric disorders and is often having an etiopathogenic role. Thus, affective disorders, anxiety, psychosis, dementia, and personality disorders frequently are accompanied by alcoholism as a co-morbidity. Moreover, some mental disorders are caused by prolonged or abusive alcohol consumption; other disorders appear as withdrawal phenomena, while in many cases alcoholism aggravates a preexisting psychiatric conditions. In some cases, alcohol consumption is intended to improve the psychiatric symptoms, such as anxiety, depression, psychosis, hypnic disorders, or side effects of medications [48]. Among the psychiatric disorders, depression and mood disorders are particularly associated with alcohol abuse. Of course, patients suffering from a major depressive disorder are at increased risk of suicide. What is important in the present context, is that studies on patients who died by suicide showed that in $30 \%$ of cases the blood alcohol level was close to or over the legal limit at the time of suicide, and half of them suffered from major depression [49]. Moreover, alcohol abuse is also suspected to dramatically (by an order of magnitude) increase the risk of suicidal behavior [50].

Still, the relationship between alcoholism, depression, and suicidal behavior is complex and clearly supported on the biochemical level. Some CSF analysis showed abnormalities of serotonin metabolism, through the dosing of the 5-hydroxyindoleacetic (5HIA) metabolite in depression and particularly in suicidal behavior. Moreover, low levels of this serotonergic metabolite are encountered in impulsivity and aggressive excesses, which are manifested especially during the consumption of ethanol. As was many times mentioned, the elements of impulsivity and aggression are known to correlate with suicidal behavior [51].

Moreover, the risk of suicide for the patients addicted to alcohol is 60 to 120 times higher than that in the general population [52]. The gender distribution shows also a much higher frequency in men, in relation to the use of alcohol before committing the suicidal act [53]. Also, alcohol consumption can cause disinhibition and increased impulsivity, which could favor mobilization to complete the suicidal act.

\section{GENETIC STUDIES}

With regard to suicidal behavior, the research on families, twins, and adoptions provided evidence 
on the significant heritability of suicide and suicide attempts, independent of the family transmission for the major psychiatric disorders. Thus, for twins the estimated heritability for suicidal risk ranges between 21-50\%, while for the broader phenotype of suicidal behavior (attempts, suicidal thoughts, and plans) it is $30-55 \%$, depending on the type of study [27]. Also, some genetic researches have attempted to identify the genes involved in suicide and suicidal behavior by studies of genetic association or following specific single nucleotide polymorphisms for studies of association.

Candidate genes for association studies were generally selected on the basis of evidence from neurobiological studies in suicidal patients. Therefore, the serotonergic system has been extensively investigated in relation with other target systems, including the dopaminergic and noradrenergic ones, derived neurotrophic factor, and, more recently, the genes related to hypothalamic-pituitary-adrenal (HPA) axis. Apparently, the environment could be also very influential in this matter, especially during the development.

Moreover, the neurobiological evidences indicated a considerable serotonergic dysfunction in suicide cases, while the genetic research has been mainly focused on genes related to the serotonin system. At the molecular level, serotonin appears to be one of the key neurotransmitters involved in the formation and control of suicidal behavior. Thus, among the genes encoding proteins involved in the serotonergic neurotransmission in suicidal persons, the most consistent scientific evidences are referring to the tryptophan hydroxylase gene, especially in the case of violent suicidal behavior [28]. In addition, promising studies have examined the serotonin receptors, monoamin oxidase receptors, serotonin $2 \mathrm{a}$ and $2 \mathrm{c}$ receptors, and tyrosine hydroxylase.

Thus, the genetic factors seem to be a significant risk factor, apart from the environmental aspects of suicidal behavior. Moreover, epidemiological and genetic studies indicated a familial aggregation of suicidal behavior, with a fivefold greater risk for relatives of persons with suicidal behavior [29, 30]. In this way, Voracek et al. [27] reported a significantly higher rate of concordance for suicidal behavior in monozygotic twins $(24.1 \%)$, as compared to dizygotic ones $(2.8 \%)$.

Also, the neurobiological and genetic studies have suggested that, generally, the suicidal behavior results from a complex interaction of multiple genes and environmental factors. The suicide attempts in this suicidal model are considered a combination of stressors and personality traits. Basically, for this model, the innate genotypic and phenotypic profile of the individuals determines their inability to cope with stressors [31]. Also, many specific genetic variants may exert additive effects on suicidal behavior by intensifying the impact of a stressor.

The researchers who analyzed the importance of genes in suicide have primarily focused on the genes involved in the serotonergic, adrenergic, noradrenergic, and dopaminergic neurotransmitter systems by the analysis of the samples taken from postmortem brain tissues of persons who completed suicide. Thus, a strong evidence supporting the association with suicidal attempts was identified for one of the most commonly studied suicide gene, the $\mathrm{S}$ allele of the serotonin transporter, but this was not found with respect to completed suicide [31]. Moreover, a study published in 2007 on bipolar patients highlighted the importance of the $2 \mathrm{p} 12$ locus in the patients with suicidal attempts, supporting previous studies on the relevance of this locus to suicidal behavior [32].

Also, the results of some studies have suggested the involvement of the dopaminergic system, in particular of the D2 receptor, in the expression of suicidal behavior. Thus, a study on 120 patients with suicidal attempts assessed the association between these attempts and two types of functional polymorphisms of the dopamine D2 receptor gene (DRD2), TaqIA and $141 C$, as compared with the control group. It was demonstrated [33] that there are significant differences of the frequency of the allele-141C Ins/ Del and TaqIA polymorphisms between patients and the healthy control group, suggesting that $D R D 2$ gene polymorphisms might be involved in the biological susceptibility to suicidal behavior.

Also, cholecystokinin (CCK) could play a significant role in suicidal behavior. In this way, Shindo et al. [34] found a strong association between the gene for CCK (the latter as a central nervous system neurotransmitter found inside certain dopaminergic neurons and also modulating dopamine release) and suicidal behavior, by analyzing the DNA of 154 suicide victims, as compared with 328 control subjects. The statistical analysis demonstrated an association between the polymorphism of $C C K-196 G / A$ and suicide occurance only in men of the studied group, and not in women.

\section{OXYTOCIN RELEVANCE}

As we mentioned at different other occasions [45], 
within the last few years there was an increase in the number of research groups and general interest for better understanding of the possible beneficial effects exerted especially by intranasal oxytocin on the main neuropsychiatric diseases, with a focus on schizophrenia [54], depression [55], frontotemporal dementia [56], autism [57], or anxiety-related behavior [58].

In relation to suicidal behavior, there are also some interesting and controversial aspects to be mentioned for the possible influence exerted by oxytocin.

These possible correlations basically started in a study performed in 2009 by the Lee et al. group [59], which mainly focused on the relations between CSF oxytocin, aggression, and personality disorder, but also did manage to increase awareness on possible relations between oxytocin and suicidal behavior through only 4 patients with suicide attempts vs. 54 controls (nonsuicidal attempters) by using the specific LHA scale.

One of the most important studies in this research area regarding the interactions between oxytocin and suicide was performed in 2012 by the Swedish group of Jokinen et al. [60], who clearly demonstrated decreased levels of oxytocin in the CSF obtained by lumbar punctures of 28 medication-free suicide attempters vs. healthy controls [60]. Moreover, the aforementioned group did manage to find some important correlations between most of the specific scales they have used to asses suicidal behavior (e.g., the Beck Suicide Intent Scale, the Freeman scale, or the Karolinska Interpersonal Violence Scale) and both CSF and plasma oxytocin levels, but only in men and not in women. However, the authors also found correlations between aggressive/violent behavior and oxytocin levels only in female suicide attempters (we would like to insist immediately on the relevance of this aspect). In fact, our research group also described earlier the complex interaction between aggressive behavior and oxytocin activities [45].

On the other hand, there are still controversies in this area of research, since some research groups failed to find any correlations between the oxytocin levels and psychiatric patients with and without recent suicide attempts. For example, this was the Deisenhammer et al. group [61], which found no differences in terms of plasma oxytocin concentrations between people with affective disorders and suicide attempts within the last 12 months vs. people with affective disorders but no suicide attempts.

Dissimilar results obtained by various research groups could be explained by differences in the established research protocol (e.g., oxytocin levels could be quite different in the CSF vs. plasma, as was in the two studies mentioned above), different medication, or the fact that suicidal behavior can exhibit extremely important gender differences $[60,62]$.

Mechanistically speaking, the implications of oxytocin in suicidal behavior could also be explained through the important effects exerted by oxytocin in stress modulation, e.g., by decreasing cortisol levels. This could be done by inhibiting the HPA axis [63].

Important correlative results between the decreased levels of plasma oxytocin and borderline personality disorder were also observed only in women patients [65]. This could be quite relevant in the present context, especially considering that certain behaviors, such as self-injury, suicidal, or parasuicidal one, are for a long time accepted in patients suffering from borderline personality disorder [65]. In addition, the aforementioned Bertsch group [64] showed correlations between traumatic childhood experiences (e.g., emotional neglect or abuse and aggressive behavior) and oxytocin concentrations in the plasma.

In fact, in direct relation to the traumatic childhood experiences, the group of Chatzittofis [66] quite recently (in 2014) showed that there is also an interesting relationship between the $\mathrm{CSF} /$ plasma oxytocin concentrations in suicide attempters and the role of a childhood trauma and revictimization. In this way, in 28 medication-free suicide attempters, these authors, using evaluation scales (such as the Karolinska Interpersonal Violence Scale), showed important correlations between revictimized suicide attempters and plasma oxytocin levels. Still, the authors failed to find any correlation between interpersonal violence exposure as a child vs. CSF and/or plasma oxytocin [66]. However, it is generally accepted in the literature that a strong correlation between childhood abuse and oxytocin concentration should exist [67].

Recent studies also described important interactions between CSF oxytocin concentrations and the schizophrenic pathology, especially in men [68]. This could be extremely relevant, especially considering the very well known and extensively accepted relationship between schizophrenia and suicidal behavior [69]. Anyway, the schizophrenic pathology has attracted an increased interest from the most important worldwide names in the effects of intranasal oxytocin studies, as, e.g., from the group of Guastella et al. [72]. These authors showed that only one dose of oxytocin nasal spray could facilitate social cognition in schizophrenia [54]. Still, there are controversies also in this area of research with previous reports 
stating significant correlations [70] or no correlations at all [71] between the CSF levels of oxytocin and schizophrenic pathology. One of the explanations for this aspect could be represented by a complex nature of the reactions, existing between administration of antipsychotics in schizophrenia and the oxytocin concentration (e.g., they might actually decrease the levels of oxytocin [72]).

In our paper we, besides describing the main introductory aspects for the concept of suicide, focused our attention on the main biological and genetical mechanisms relevant for the suicidal behavior. Moreover, considering the latest interests in the current literature on the relevance of central oxytocin in various superior cognitive behaviors, we also desribed how important oxytocin could be in the context of suicidal behavior.

Acknowledgments. M. Padurariu, A. Ciobica, and R. Dobrin are supported by the PN-II-RU-TE-2014-4-1886 grant called "A complex study regarding the relevance of oxytocin administration in some animal models of neuropsychiatric disorders," No. 120, 01/10/2015 (Romania).

This publication is a review of the literature data; thus, it does not require the confirmation of compliance with ethical standards for experimental works.

The authors, M. Padurariu, R. Prepelita, A. Ciobica, R. Dobrin, D. Timofte, C. Stefanesku, and R. Chirita, confirm that they have no conflicts of any kind related to the commercial or financial problems, relations with organizations or persons, which could in any way be associated with the investigation, and with the relationship of the co-authors of the article.

М. Падураріу 1 , Р. Препеліта ${ }^{1}$, А. Ціобіка ${ }^{2,3}$, Р. Добрін Д. Тімофте ${ }^{1}$, K. Стефанеску ${ }^{1}$, Р. Чіріта ${ }^{1}$

\section{КОНЦЕПЦІЯ СУЇЦИДУ: НЕЙРОФІЗІОЛОГІЧНІ ТА ГЕНЕТИЧНІ ТЕОРІЇ ТА МОЖЛИВИЙ ВПЛИВ СИСТЕМИ ОКСИТОЦИНУ}

\footnotetext{
1 Університет медицини і фармації ім. Гр. Т. Попа, Ясси (Румунія).

2 Університет ім. А. І. Куза, Ясси (Румунія).

${ }^{3}$ Центр біомедичних досліджень Румунської Академії, Ясси (Румунія).

P е 3 ю м е
}

Суїцидальна поведінка - це дії, в результаті яких особа намагається позбавити себе життя, усвідомлюючи наслідки таких дій. У даному огляді, окрім опису основних загаль- них аспектів концепції суїциду, ми концентрували увагу на основних нейрофізіологічних та генетичних аспектах, котрі мають відношення до цього вкрай важко контрольованого та повного протиріч типу поведінки. Окрім того, враховуючи велику цікавість, яку викликає в сучасній літературі задіяність центральної окситоцинової системи в контроль когнітивної поведінки вищих типів, ми надали короткий опис того, наскільки ефекти окситоцину можуть бути важливими в контексті суїцидальної поведінки.

\section{REFERENCES}

1. K. Hawton, K. van Heeringen, "Suicide," Lancet, 373, 13721381 (2009).

2. M. Miller, D. Azrael, and C. Barber, "Suicide mortality in the United States: the importance of attending to method in understanding population-level disparities in the burden of suicide," Annu. Rev. Publ. Health, 33, 393-408 (2012).

3. J. Tintinalli, Emergency Medicine: A Comprehensive Study Guide (Emergency Medicine Tintinalli), McGraw-Hill Comp., New York (2010).

4. A. Leenaars, Life Span Perspectives of Suicide, Plenum, New York (1991).

5. F. Tudose, C. Tudose, and L. Dobranici, Psihopatologie şi Psihiatrie Pentru Psihologi, Infomedica, Bucureşti (2000).

6. G. Scripcaru, V. Astarastoae, P. Boişteanu, et al., Psihiatrie Medico-Legală, Polirom, Iasi (2002).

7. A. Ohberg, J. Lonnqvist, S. Sarna, et al., "Trends and availability of suicide methods in Finland. Proposals for restrictive measures," Br. J. Psychiat., 166, 35-43 (1995).

8. G. Stone, Suicide and Attempted Suicide: Methods and Consequences, Carroll \& Graf New York (2001).

9. R. P. Dutton, "Pathophysiology of Traumatic Shock" Prog. Search Anesth. Preoper Med. Pain, 20, No. 1, 7-10 (2001).

10. R. Maris, A. Berman, and M. Silverman, Comprehensive Textbook of Suicidology, Guildford Press, New York (2001).

11. HKJC Centre for Suicide Research and Prevention, University of Hong Kong, Method Used in Completed Suicide, Hong Kong (2006).

12. A. Kellermann, F. Rivara, and G. Somes, "Suicide in the home in relation to gun ownership," New Eng. J. Med., 327, 467-472 (1992).

13. P. Hay, L. Denson, M. van Hoof, and N. Blumenfeld, "The neuropsychiatry of carbon monoxide poisoning in attempted suicide: a prospective controlled study," J. Psychosom. Res., 53, 699-708 (2002).

14. D. Dolinak, E. Matshes, and E. Lew, Forensic Pathology: Principles and Practice, Acad. Press, Sandiego (2005).

15. G. Dingman, "Characteristics of patients with serious suicidal intention who ultimately commit suicide," Hosp. Com. Psychiat., 39, 295-299 (1998).

16. K. Inder, T. Handley, A. Johnston, et al., "Determinants of suicidal ideation and suicide attempts: parallel cross-sectional analyses examining geographical location," BMC Psychiat. (2014)

17. F. Beauchamps and J. Childress, Principles of Biomedical Ethics, Oxford Univ. Press, New York (1994).

18. W. Dwight and C. Chapman, "Reviewed Work: Man against Himself, by Karl A. Menninger," Science \& Society. 2, 559562 (1938). 
19. H. Fenichel and D. Rapaport, The Collected Papers of Otto Fenichel, Acad. Press, New York (1987).

20. V. Ajdacic-Gross, "Methods of suicide: international suicide patterns derived from the WHO mortality database," Bull. World Health Organ., 86, 726-732 (2008).

21. R. O'Connor, C. Platt, S. Gordon, International Handbook of Suicide Prevention: Research, Policy and Practice, John Wiley and Sons, New York (2011).

22. J. Geddes, P. Jonathan, G. Rebecca, and M. Mayou, Psychiatry, Oxford Univ. Press, Oxford (2003).

23. J. Tintinalli, Emergency Medicine: A Comprehensive Study Guide (Emergency Medicine (Tintinalli), McGraw-Hill Comp., New York (2010).

24. P. Yip, "Means restriction for suicide prevention," Lancet, 379, 2393-2399 (2012).

25. A. Regan, Culture and Mental Health Sociocultural Influences, Theory, and Practice., Wiley-Blackwell, Chichester (2009).

26. E. Krug, World Report on Violence and Health, Vol. 1, World Health Organ., Genève (2002).

27. M. Voracek and L. Loibl, Genetics of Suicide: a Systematic Review of Twin Studies, Klin Wochenschr, Wien, 463-475 (2007).

28. T. Zupanc, P. Pregelj, and A. Paska, "Tryptophan hydroxylase 2 (TPH 2) single nucleotide polymorphisms, suicide, and alcohol-related suicide," Psychiat. Danub., 2, 332-336 (2013).

29. A. Roy and N. Segal, "Suicidal behavior in twins: a replication," J. Affect Disord., 66, 71-74 (2001).

30. G. Turecki, "Suicidal behavior: is there a genetic predisposition," Bipolar Disord., 3, 335-349 (2001).

31. R. Clayden, A. Zaruk, D. Meyre, et al., "The association of attempted suicide with genetic variants in the SLC6A4 and TPH genes depends on the definition of suicidal behavior: a systematic review and meta-analysis," Transl. Psychiat., 2, 166 (2012)

32. V. Willour, P. Zandi, J. Badner, et al., "Attempted suicide in bipolar disorder pedigrees: evidence for linkage to $2 \mathrm{p} 12$," Biol. Psychiat., 61, 725-727 (2007).

33. A. Suda, C. Kawanishi, I. Kishida, et al, "Dopamine D2 receptor gene polymorphisms are associated with suicide attempt in the Japanese population," Neuropsychobiology, 59, 130-134 (2009).

34. S. Shindo and N. Yoshioka, "Polymorphisms of the cholecystokinin gene promoter region in suicide victims in Japan," Foren. Sci. Int., 150, 85-90 (2005).

35. J. Roggenbach, B. Muller-Oerlinghausen, and L. Franke, "Suicidality, impulsivity and aggression - is there a link to 5HIAA concentration in the cerebrospinal fluid?" Psychiat. Res., 113, 193-206 (2002).

36. J. Mann, P. McBride, G. Anderson, and T. Mieczkowski, "Platelet and whole blood serotonin content in depressed inpatients: Correlations with acute and life-time psychopathology," Biol. Psychiat., 32, 243-257 (1992).

37. L. Almeida-Montes, V. Valles-Sanchez, J. Moreno-Aguilar, et al., "Relation of serum cholesterol, lipid, serotonin and tryptophan levels to severity of depression and to suicide attempts," J. Psychiat. Neurosci., 25, 371-377 (2000).

38. D. Lester, "The concentration of neurotransmitter metabolites in the cerebrospinal fluid of suicidal individuals: A metaanalysis," Pharmacopsychiatry, 28, 45-50 (1995).

39. S. Tyano, G. Zalsman, H. Ofek, et al., "Plasma serotonin levels and suicidal behavior in adolescents," Eur. Neuropsychopharmacol., 16, 49-57 (2006).
40. G. Pandey and Y. Dwivedi, Peripheral Biomarkers for Suicide. The Neurobiological Basis of Suicide, CRC Press, Boca Raton (FL) (2012).

41. C. Stockmeier, L. Shapiro, G. Dilley, et al., "Increase in serotonin-1A autoreceptors in the midbrain of suicide victims with major depression - postmortem evidence for decreased serotonin activity," J. Neurosci., 18, 7394-7401 (1998).

42. S. Lowther, F. DePaermentier, S. Cheetham, et al., "5-HT1A receptor binding sites in post-mortem brain samples from depressed suicides and controls," J. Affect Disord., 42, 199207 (1997).

43. R. Davidson, K. Putnam, and C. Larson, "Dysfunction in the neural circuitry of emotion regulation - a possible prelude to violence," Science, 289, 591-594 (2000).

44. D. Purselle and C. Nemeroff, "Serotonin transporter: a potential substrate in the biology of suicide," Neuropsychopharmacology, 28, 613-619 (2003).

45. M. Padurariu, R. Prepelita, A. Ciobica, et al., "Short review on the aggressive behavior: genetical, biological aspects and oxytocin relevance," Int. Lett. Natur. Sci., 52, 43-53 (2016).

46. J. Mann, "Role of the serotonergic system in the pathogenesis of major depression and suicidal behavior," Neuropsychopharmacology, 21, S99-S105 (1999).

47. M. Nock, G. Borges, E. Bromet, et al., "Suicide and suicidal behavior," Epidem. Rev., 30, 133-154 (2008).

48. G. Zarkin, J. Bray, A. Aldridge, et al., "The effect of alcohol treatment on social costs of alcohol dependence: results from the COMBINE study," Med. Care, 48, 396-401 (2010).

49. H. C. Wilcox, K. R. Conner, and E. D. Caine, "Association of alcohol and drug use disorders and completed suicide: an empirical review of cohort studies," Drug. Alcohol. Depend., 7, Suppl. 76, S11-S19 (2004).

50. M. Virkkunen and M. Linnoila, "Brain serotonin, type II alcoholism and impulsive violence," J. Study Alcohol. Suppl., Sept., 163-169 (1993).

51. G. N. Pandey, "Biological basis of suicide and suicidal behavior," Bipolar Disord., 15, No. 5, 524-541 (2013).

52. D. Grossman and G. DeGaetano, Stop Teaching Our Kids to Kill, Crown Publ., New York (1999).

53. S. Fudalej, M. Ilgen, M. Fudalej, et al., "Clinical and genetic risk factors for suicide under the influence of alcohol in a polish sample", Alcogol and Alcohol., 44, No. 5, 437-442 (2009)

54. A. J. Guastella, P. B. Ward, I. B. Hickie, et al., "A single dose of oxytocin nasal spray improves higher-order social cognition in schizophrenia," Schizophr. Res., 168, No. 3, 628-633 (2015).

55. A. Clarici, S. Pellizzoni, S. Guaschino, et al., "Intranasal administration of oxytocin in postnatal depression: implications for psychodynamic psychotherapy from a randomized doubleblind pilot study," Front. Psychol., 6, Apr., 426 (2015).

56. E. C. Finger, J. MacKinley, M. Blair, et al., "Oxytocin for frontotemporal dementia: a randomized dose-finding study of safety and tolerability," Neurology, 84, No. 2, 174-181 (2015).

57. A. J. Guastella, S. L. Einfeld, K. M. Gray, et al., "Intranasal oxytocin improves emotion recognition for youth with autism spectrum disorders," Biol. Psychiat., 67, No. 7, 692-694 (2010).

58. A. Hernádi, A. Kis, O. Kanizsár, et al., "Intranasally administered oxytocin affects how dogs (Canis familiaris) react to the threatening approach of their owner and an unfamiliar experimenter," Behav. Process., 119, 1-5 (2015). 
59. R. Lee, C. Ferris, L. D. Van de Kar, and E. F. Coccaro, "Cerebrospinal fluid oxytocin, life history of aggression, and personality disorder," Psychoneuroendocrinology, 34, No. 10, 1567-1573 (2009).

60. J. Jokinen, A. Chatzittofis, C. Hellström, et al., "Low CSF oxytocin reflects high intent in suicide attempters," Psychoneuroendocrinology, 37, No. 4, 482-490 (2012).

61. E. A. Deisenhammer, S. Hofer, O. Schwitzer, et al., "Oxytocin plasma levels in psychiatric patients with and without recent suicide attempt," Psychiat. Res., 200, No. 1, 59-62 (2012).

62. G. Domes, A. Lischke, C. Berger, et al., "Effects of intranasal oxytocin on emotional face processing in women," Psychoneuroendocrinology, 35, 83-93 (2010).

63. A. Ciobica, I. M. Balmus, and M. Padurariu, "Is oxytocin relevant for the affective disorders?" Acta Endocrinol., 12, 6571 (2016).

64. K. Bertsch, I. Schmidinger, I. Neumann, and S. Herpertz, "Reduced plasma oxytocin levels in female patients with borderline personality disorder," Horm. Behav., 63, 424-429 (2013).

65. D. Gardner and R. Cowdry, "Suicidal and parasuicidal behavior in borderline personality disorder," Psychiat. Clin. North Am., 8, 389-403 (1985).

66. A. Chatzittofis, P. Nordström, K. Uvnäs-Moberg, et al., "CSF and plasma oxytocin levels in suicide attempters, the role of childhood trauma and revictimization," Neuroendocrinol. Lett., 35, 213-217 (2014).

67. C. Heim, L. Young, D. Newport, et a1., "Lower CSF oxytocin concentrations in women with a history of childhood abuse," Mol. Psychiat., 14, 954-958 (2009).

68. D. Sasayama, K. Hattori, T. Teraishi, et al., "Negative correlation between cerebrospinal fluid oxytocin levels and negative symptoms of male patients with schizophrenia," Schizophr. Res., 139, 201-206 (2012).

69. K. Hor and M. Taylor, "Suicide and schizophrenia: a systematic review of rates and risk factors," J. Psychopharmacol., 24, 81$90(2010)$.

70. H. Beckmann, R. Lang, and W. Gattaz, "Vasopressin-oxytocin in cerebrospinal fluid of schizophrenic patients and normal controls," Psychoneuroendocrinology, 10, 187-191 (1985).

71. D. Glovinsky, K. Kalogeras, D. Kirch, et al., "Cerebrospinal fluid oxytocin concentration in schizophrenic patients does not differ from control subjects and is not changed by neuroleptic medication," Schizophr. Res., 11, 273-276 (1994).

72. A. Sirzen-Zelenskaya, A. Gonzalez-Iglesias, J. Boutet de Monvel, et al., "Prolactin induces a hyperpolarising current in rat paraventricular oxytocinergic neurons," $J$. Neuroendocrinol., 23, 883-893 (2011). 